\title{
PENGARUH KOMITMEN AFEKSI, KOMITMEN KONTINUM, DAN KOMITMEN NORMATIF TERHADAP LOYALITAS PELANGGAN SALON KECANTIKAN MARTHA TILAAR DI KOTA BANDA ACEH
}

\author{
Zahriatul 'Aini ${ }^{1 *}$ \\ ${ }^{1}$ Program Studi Administrasi Perkantoran Politeknik Kutaraja \\ Telp. 0651- 8016378 \\ *Email: zahriatulaini@yahoo.com
}

\begin{abstract}
ABSTRAK
Penelitian ini bertujuan untuk menganalisis pengaruh Komitmen Afeksi, Komitmen Kontinum dan Komitmen Normatif terhadap Loyalitas Pelanggan salon kecantikan Martha Tilaar di kota Banda Aceh. Model analisis dalam penelitian ini adalah regresi linier berganda dengan tingkat signifikansi $5 \%$. Penelitian ini menemukan bahwa secara simultan terdapat pengaruh signifikan antara Komitmen Afeksi, Komitmen Kontinum, Komitmen Normatif terhadap Loyalitas Pelanggan Salon Kecantikan Martha Tilaar. (Sig $\mathrm{F}=$ $0,000<\alpha=0,05)$. Dan secara parsial Komitmen Kontinum dan Komitmen Normatif berpengaruh signifikan $(\alpha<=0,05)$ terhadap Loyalitas Pelanggan salon Martha Tilaar dengan signifikansi sebesar sig $\mathrm{t}=0,007$ dan sig $\mathrm{t}=0,003$, sedangkan Komitmen Afeksi tidak signifikan terhadap Loyalitas Pelanggan salon kecantikan Martha Tilaar dengan signifikansi sebesar sig $\mathrm{t}=1,914$
\end{abstract}

\section{Kata Kunci: Komitmen Afeksi, Komitmen Kontinum, Komitmen Normatif, Loyalitas Pelanggan}

\section{PENDAHULUAN}

Pada saat ini perkembangan usaha bisnis dalam era globalisasi semakin pesat ditandai dengan tingkat persaingan antar perusahaan yang semakin tinggi dan ketat. Keadaan tersebut menyebabkan perusahaan pada umumnya berusaha untuk mempertahankan kelangsungan hidup, mengembangkan perusahaan, memperoleh laba optimal serta dapat memperkuat posisi dalam menghadapi perusahaan pesaing dimana untuk mencapai tujuan tersebut tidak terlepas dari usaha pemasaran yang harus dipikirkan dan direncanakan. Menyadari hal itu, pemasaran merupakan salah satu kegiatan pokok yang dilakukan perusahaan untuk mencapai tujuan.

Pemasaran merupakan salah satu kegiatan pokok yang dilakukan oleh perusahaan untuk mempertahankan kelangsungan hidupnya, tetapi dalam pemasaran modern seperti ini paragdima pemasaran telah bergeser, tidak hanya menciptakan transaksi untuk mencapai keberhasilan pemasaran tetapi perusahaan juga harus meningkatkan kualitas jasa sehingga dapat mencapai komitmen dan loyalitas pelanggan dalam waktu yang panjang.

Perkembangan pemasaran berawal dari tukarmenukar barang secara sederhana tanpa menggunakan alat tukar berupa uang ataupun logam mulia. Dengan berkembangnya ilmu pengetahuan, maka semakin dibutuhkannya suatu alat tukar yang berlaku umum dan untuk itulah diciptakannya uang. Di samping itu, manusia juga memerlukan jasa yang mengurus hal-hal tertentu, sehingga jasa menjadi salah satu bagian utama dalam pemasaran.

Perusahaan dalam memasarkan barang dan jasa selalu dihadapkan pada pertanyaan, "mengapa konsumen mau membeli kembali barang atau jasa tertentu?" jawabannya tidak dapat diterangkan secara langsung dari pengamatannya saja, tetapi dibutuhkan analisa pemasaran jasa dan perilaku konsumen yang lebih mendalam. Hal ini akan banyak membantu bagi manajer pemasaran untuk memahami "mengapa" dan "bagaimana" perilaku konsumen tersebut, sehingga perusahaan dapat mengembangkan, menentukan harga, mempromosikan, dan mendistribusikan barangnya secara baik. Menurut Supriyanto dan Lestari (2015) Setiap perusahaan bertujuan untuk memaksimalkan kekayaan dari pemegang sahamnya. Sehingga pemasaran menjadi penting dalam menentukan keberhasilan dalam mencapai tujuan tersebut.

Menurut Kotler (2003) perilaku konsumen mempelajari mengenai bagaimana individu, kelompok, dan organisasi memilih, membeli, menggunakan, dan menentukan produk, jasa, 
ide, atau pengalaman yang memuaskan kebutuhan dan keinginan mereka. Perilaku konsumen dipengaruhi oleh faktor budaya, sosial, personal, dan psikologis. Konsumen memperoleh berbagai pengalaman dalam pembelian produk, mengkonsumsi produk, dan merek produk apa yang disukainya. Ketika pengalaman masa lalunya menyenangkan, pada suatu merek tertentu, maka konsumen mungkin akan lebih menunjukkan perilaku yang konsisten sepanjang waktu terhadap merek tersebut.

Perilaku yang konsisten sepanjang waktu menggambarkan loyalitas terhadap suatu objek tertentu. Konsumen yang loyal pada suatu merek tertentu (loyalitas pelanggan) telah menjadi pedoman bagi kinerja perusahaan. Setidaknya loyalitas pelanggan telah menjadi salah satu tolak ukur bagi keberhasilan aktivitas pemasaran. Oleh karena itu, loyalitas pelanggan merupakan tujuan bagi perencanaan pasar strategik dalam jangka panjang, dan menjadi basis penting bagi pengembangan

Menurut Dick dan Basu (1994), salah satu tujuan utama aktivitas pemasaran sering kali dilihat dari pencapaian loyalitas pelanggan melalui strategi pemasaran. Istilah loyalitas pelanggan menunjukan pada kesetiaan pelanggan pada objek tertentu, seperti pada merek, produk, jasa atau toko. Pada umumnya merek sering kali dijadikan sebagai objek loyalitas pelanggan. Loyalitas merek (brand loyality) mencerminkan loyalitas pelanggan pada merek tertentu. Loyalitas pelanggan memberikan dampak yang signifikan bagi profitabilitas perusahaan. Pelanggan yang loyal kemungkinan akan menunjukkan sikap dan prilaku positif, seperti pembelian ulang merek yang sama dan rekomendasi positif yang dapat mempengaruhi pelanggan lain untuk menggunakan merek tersebut (Arlan, 2006: 63).

Sebagai salah satu aspek dalam pemasaran, komitmen merupakan keinginan yang berkelanjutan untuk membangun suatu hubungan yang bernilai (Moorman, at. al, 1992, p. 23). Dalam hal ini lebih menekankan pengertian komitmen dari unsur perilaku sebagai upaya untuk mempertahankan dan menjaga hubungan jangka panjang antar kedua belah pihak agar hubungan ini lebih bernilai. Sedangkan beberapa peneliti mendefinisikan komitmen sebagai suatu ikatan psikologis pelanggan, keprihatinan terhadap kesejahteraan di masa yang akan datang dan identifikasi dan kebanggaan memiliki asosiasi dengan organisasi (Garbarino \& Johnson, 1999).
Fullerton and Taylor, (2000 Jasfar, 2005) bahwa komitmen konsumen akan lebih baik bila melalui loyalitas. Mereka membedakan konsep komitmen ke dalam tiga katagori, yaitu:

1. Komitmen afeksi, yaitu komitmen yang merujuk pada pembagian nilai (shared values) dan kemurahan hati (benevolence).

2. Komitmen kontinum, yaitu komitmen yang merujuk kepada pengorbanan dan ketergantungan.

3. Komitmen normative, yaitu komitmen yang merujuk kepada konstruk menyeluruh yang menjadi penyebab tumbuhnya rasa berbagi tanggung jawab.

Jadi komitmen adalah dedikasi dan keinginan yang bertahan dari seseorang atau kelompok dalam mempertahankan hubungan pembeli dan penjual sebagai kelanjutan hubungan antar patner yang bernilai. Kelanjutan hubungan yang terjadi akan menyebabkan terjadinya loyalitas.

Bisnis jasa saat ini sedang berkembang pesat di Indonesia khususnya di Banda Aceh, saat ini banyak bermunculan bisnis jasa seperti salon kecantikan, biro perjalanan wisata/tiket, rumah sakit, penginapan/indekos, percetakan, pengiriman barang dan sebagainya. Salon kecantikan merupakan suatu usaha jasa yang banyak diminati oleh sebagian kaum wanita di kota Banda Aceh, sehingga banyak bermunculan usaha sejenis di wilayah tersebut.

Manusia mempunyai banyak kebutuhan yang harus dipenuhi, baik kebutuhan yang bersifat biogenetik seperti rasa lapar dan haus maupun kebutuhan yang bersifat psikogenetik, yaitu kebutuhan akan pengakuan, penghargaan dan rasa kepemilikan. Kebutuhan adalah keadaan merasa tidak memiliki kepuasan dasar dan bersifat naluriah sedangkan keinginan adalah hasrat akan pemuas tertentu dari kebutuhan tersebut, sehingga keinginan merupakan kebutuhan buatan yaitu kebutuhan yang dibentuk oleh lingkungan hidupnya. Keinginan terhadap suatu produk yang didukung dengan kemampuan serta kesediaan membelinya akan menciptakan permintaan. Contohnya, keinginan wanita untuk selalu ingin tampil cantik dan segar. Mereka akan rela menghabiskan waktunya untuk mempercantik diri di salon kecantikan. Seperti mempercantik kulit, ataupun rambut.

Martha Tilaar merupakan salah satu salon kecantikan ternama di Indonesia bahkan sekarang sudah mendunia. Sehingga Martha Tilaar mempunyai banyak cabang di seluruh 
Indonesia, termasuk di Kota Banda Aceh. Martha Tilaar berbeda dari salon lain karena Martha Tilaar memiliki produk sendiri untuk salonnya, salah satunya adalah Sariayu. Sariayu Martha Tilaar sangat identik sekali sebagai produk lokal. Pelanggan mengetahui bahwa produk Martha Tilaar sesungguhnya sudah mendunia, berkualitas, dan bergengsi.

Fenomena yang terjadi adalah bahwa saat ini Aceh merupakan salah satu provinsi di Indonesia yang mayoritas penduduknya beragama islam dan pemerintah daerah Aceh menerapkan syari'at islam yang mengharuskan masyarakatnya mematuhi hukum-hukum islam. Contohnya, para wanita wajib mengenakan busana muslimah yang mengharuskan menutup aurat dari kepala sampai dengan kaki, sehingga setelah mengkonsumsi jasa salon kecantikan tidak telihat. Mungkin seharusnya didapatkan permintaan pelanggan akan salon kecantikan

\section{Populasi dan Sampel}

\section{METODE PENELITIAN}

Populasi dalam penelitian ini pelanggan salon kecantikan Martha Tilaar yang melakukan pembelian produkatau jasa Martha Tilaar.

\section{Teknik Pengambilan Sampel}

Sedangkan penarikan sampel dilakukan dengan menggunakan metode Convinience Sampling (sampel mudah) terhadap pelanggan yang pernah melakukan pembelian jasa di salon kecantikan Martha Tilaar lebih dari dua kali.

\section{Operasional Variabel}

Variabel yang dioperasionalkan dalam penelitian ini adalah Loyalitas Pelanggan (Y) sebagai

\section{PEMBAHASAN}

Berdasarkan hasil persamaan regresi berganda tersebut, masing-masing variabel dapat diinterpretasikan pengaruhnya terhadap loyalitas pelanggan adalah sebagai berikut:

1. Dalam penelitian diperoleh nilai konstanta sebesar 0.504. Artinya jika komitmen afeksi $\left(X_{1}\right)$, komitmen kontinum $\left(X_{2}\right)$, dan komitmen normatif $\left(X_{3}\right)$ bernilai nol maka besarnya loyalitas pelanggan salon MarthaTilaar di Banda Aceh adalah sebesar 0.504.

2. Koefisien regresi komitmen afeksi $\left(X_{1}\right)$ sebesar 0.155 . Artinya setiap perubahan dalam satu unit variabel komitmen afeksi saat ini menurun, tetapi fakta yang di dapat salon kecantikan khususnya di Kota Banda Aceh tidak pernah sepi akan pelanggan.

Begitu juga dengan fakta yang di dapat sekarang, bahwa kebanyakan para wanita sudah mengisi hampir di separuh pekerjaan yang ada. Dengan wanita yang bekerja, pendapatan suatu rumah tangga menjadi meningkat yang menyebabkan setelah kebutuhan dasar terpenuhi, berbagai macam keinginan timbul. Seperti halnya wanita ingin terlihat lebih cantik, dengan begitu permintaan akan salon kecantikan tetap ada.

Berdasarkan penjelasan sebelumnya, hipotesis yang diuji dalam penelitian ini adalah diduga komitmen afeksi, komitmen kontinum dan komitmen normatif berpengaruh terhadap loyalitas pelanggan salon kecantikan Martha Tilaar.

Peneliti mengambil sampel sejumlah 100 orang responden yang sekarang menggunakan jasa salon kecantikan Martha Tilaar.

\section{Peralatan Analisis Data}

Data yang diperoleh akan diolah menggunakan statistic dengan bantuan komputer melalui bantuan program Statistical Producted and Service Solution (SPSS). Peralatan statistik yang digunakan untuk menganalisis data dari permasalahan penelitian adalah menggunakan analisis regresi linear berganda (multiple linear regression).

variabel dependen dan Komitmen Afeksi $\left(X_{1}\right)$, Komitmen Kontinum $\left(X_{2}\right)$, dan Komitmen Normatif $\left(X_{3}\right)$ sebagai variabel independen.

maka secara relatif akan meningkatkan loyalitas pelanggan salon Martha Tilaar di Banda Aceh sebesar 15.5\%, dengan asumsi variabel lain dianggap konstan.

3. Koefisien regresi komitmen kontinum $\left(\mathrm{X}_{2}\right)$ sebesar 0.394. Artinya bahwa setiap perubahan dalam satu unit variabel komitmen kontinum maka secara relatif akan meningkatkan loyalitas pelanggan salon Martha Tilaar di Banda Aceh sebesar 39.4\% dengan demikian semakin konsumen merasa puas dengan jasa yang diberikan, maka secara relatif akan meningkatkan loyalitas pelanggan salon Martha Tilaar di Banda Aceh. 
4. Koefisien regresi komitmen normatif $\left(X_{3}\right)$ sebesar 0.343. Artinya bahwa setiap perubahan dalam satu unit variabel komitmen normatif maka secara relatif akan meningkatkan loyalitas pelanggan salon Martha Tilaar di Banda Aceh sebesar 34.3\%.

Nilai $\mathrm{R}$ Square adalah 0,682 menunjukkan bahwa variabel independen mampu menjelaskan 68,2 \% variabel dependen, sedangkan sisanya yaitu sebesar 31,8 \% dijelaskan oleh variabel lain di luar variabel independen atau dipengaruhi oleh variabel lain yang tidak termasuk dalam penelitian ini. Nilai koefisien korelasi (R) sebesar 0,826 menunjukkan bahwa kuat hubungan variabel independen terrhadap variabel dependen sebesar $82,6 \%$.

Berdasarkan hasil regresi berganda di atas dengan menggunakan uji-F terlihat bahwa komitmen afeksi, komitmen kontinum dan komitmen normatif berpengaruh signifikan terhadap loyalitas pelanggan Martha Tilaar. Hal ini menunjukkan bahwa Ha1, Ha2,Ha3dapat diterima, dengan kata lain komitmen afeksi, komitmen kontinum dan komitmen normatif secara signifikan dapat berpengaruh terhadap loyalitas pelanggan Martha Tilaar secara simultan.

Berdasarkan hasil uji-t terlihat bahwa secara parsial komitmen afeksi tidak berpengaruh secara signifikan terhadap loyalitas pelanggan Martha Tilaar. $\mathrm{Hal}$ ini berarti menunjukkan bahwa hipotesis Ha1 ditolak. Artinya secara parsial komitmen afeksi tidak berpengaruh secara signifikan terhadap loyalitas pelanggan Martha Tilaar. Hasil ini tidak sejalan dengan penelitian sebelumnya bisa saja disebabkan oleh kondisi servise jasa yang berbeda.

Berdasarkan hasil uji-t terlihat bahwa secara parsial Komitmen kontinum berpengaruh secara signifikan terhadap loyalitas pelanggan Martha Tilaar. Hal ini berarti menunjukkan bahwa hipotesis Ha2 diterima. Artinya secara parsial komitmen kontinum berpengaruh secara signifikan terhadap loyalitas pelanggan Martha Tilaar.

Berdasarkan hasil uji-t terlihat bahwa secara parsial Komitmen normatif berpengaruh secara signifikan terhadap loyalitas pelanggan Martha Tilaar. Hal ini berarti menunjukkan bahwa hipotesis Ha3 diterima. Artinya secara parsial komitmen normatif berpengaruh secara signifikan terhadap loyalitas pelanggan Martha Tilaar.

\section{KESIMPULAN DAN SARAN}

\section{Kesimpulan}

Berdasarkan pembahasan, dapat diambil beberapa kesimpulan sebagai berikut:

a. Berdasarkan hasil regresi linear berganda diperoleh penjelasan bahwa semua variabel yang teliti komitmen afeksi, komitmen kontinum dan komitmen normatif mempunyai koefisien korelasi (hubungan) yang cukup erat serta mempunyai pengaruh yang cukup kuat terhadap loyalitas pelanggan salon kecantikan Martha Tilaar.

b. Berdasarkan hasil penelitian variabel yang mempunyai pengaruh dominan terhadap loyalitas pelanggan salon kecantikan Martha Tilaar Banda Aceh adalah komitmen kontinum karena mempunyai nilai koefisien regresi lebih besar dibandingkan dengan variabel lainnya.

c. Berdasarkan hasil uji-F atau secara simultan menunjukkan bahwa semua variabel yang diteliti berpengaruh secara signifikan terhadap loyalitas pelanggan salon kecantikan Martha Tilaar Banda Aceh, hal ini karena diperoleh nilai $\quad F_{\text {Hitung }}>F_{\text {Tabel }}$ pada tingkat signifikansi $\alpha=5 \%$.

d. Berdasarkan hasil Uji-t (secara persial) menunjukkan bahwa komitmen kontinum dan komitmen normatif mempunyai pengaruh secara signifikan terhadap loyalitas pelanggan salon kecantikan Martha Tilaar Banda Aceh dengan demikian hipotesis $\mathrm{H}_{\mathrm{a} 2}$, dan $\mathrm{H}_{\mathrm{a}}$ diterima dan menolak hipotesis $\mathrm{H}_{02}$, dan $\mathrm{H}_{03}$. Sedangkan komitmen afeksi tidak mempunyai pengaruh yang signifikan terhadap loyalitas pelanggan salon kecantikan Martha Tilaar sehingga menerima hipotesis $\mathrm{H}_{01}$ dan menolak hipotesis $\mathrm{H}_{\mathrm{a} 1}$.

\section{Saran}

a. Manajemen Martha Tilaar agar tetap mempertahankan pelanggan dengan melengkapi alamat, nomor telepon pelanggan dalam database sehingga memudahkan komunikasi antara pelanggan dan Martha Tilaar sehingga akan selalu tercipta hubungan yang baik dengan pelanggan.

b. Manajemen Martha Tilaar harus terus mempertahankan dan meningkatkan kualitas jasa dan service jasa yang telah ada.

c. Berdasarkan hasil penelitian, komitmen kontinum adalah variabel yang paling berpengaruh dan kaitannya adalah dengan ketergantungan pelanggan dengan produk, sehingga ada baiknya jika Martha Tilaar 
mempertahankan kualitas produk sehingga loyalitas pelanggan tetap terjaga.

d. Peneliti selanjutnya agar menambah variabel lain yang ada secara teoritis selain variabel dalam penelitian ini yang berpengaruh terhadap loyalitas pelanggan.

\section{DAFTAR KEPUSTAKAAN}

Akhmal, A., Hermawan, I., \& Fitra, N. (2016). ANALISIS KEPUASAN MAHASISWA TERHADAP PELAYANAN PERGURUAN TINGGI SWASTA DI KOTA MEDAN (STUDI KASUS: STIM SUKMA MEDAN). Jurnal Bis-A: Jurnal Bisnis Administrasi, 5(2), 1-13.

Arlan Tjahyadi, Rully. (2006). "Brand Trust Dalam Konteks Loyalitas Merek: Peran karakteristik Merek, Karakteristik Perusahaan Dan Karakteristik Hubungan Pelanggan-Merek." Jurnal Manajemen, Vol. 6, No.1

Dick dan Basu. (1994). Manajemen Pemasaran Jasa: Teori dan Praktek. Edisi Pertama. Salemba Empat. Jakarta

Dwyer, F. Robert at, Paul H. Schurr, dan Sejo Oh, (1987). Developing Buyer-Seller Relationship. Journal of Marketing, Vol. 51 (april), p.11-27.

Garbarino, E. \& Johnson, M. S. (1999). The Different Roles of Satisfaction, Trust, and Commitment in Customer Relationship. Journal of Marketing, 63(April), 70-87

Idris, I., Hanum, Z., \& Wahyudi, D. (2015). ANALISIS EKUITAS MEREK PONSEL SAMSUNG SEBAGAI USULAN UNTUK
MEMBIDIK SEGMENTASI BARU DI KOTA MEDAN. Jurnal Bis-A: Jurnal Bisnis Administrasi, 4(2), 75-78.

Jasfar, Farida. (2005). Kualitas Jasa dan Hubungannya dengan Loyalitas serta Komitmen Konsumen: Studi Pada Salon Kecantikan. Jurnal Siasat Bisnis, hal.97118.

Kotler, Phillip. (2003). Manajemen Pemasaran: Analisi, Perencanaan, Implementasi dan Pengendalian. Edisi Kedelapan. Salemba Empat. Jakarta

Moorman, Christine, Gerald Zaltman dan Rohit Deshpande. (1992). Relationship Between Providers and User of Marketing Research: The Dynamics of Trust Within and Between Organization. Journal of Marketing Research, 29 (August), p.314329.

Sihombing, I. K., \& Fitriani, N. (2015). HUBUNGAN INSENTIF (PREMI) TERHADAP MOTIVASI KERJA KARYAWAN PT. PERKEBUNAN NUSANTARA III (PERSERO) MEDAN. Jurnal Bis-A: Jurnal Bisnis Administrasi, 4(1), 08-16.

Supriyanto, S., \& Lestari, W. (2015). ANALISIS KINERJA KEUANGAN DENGAN MENGGUNAKAN METODE ECONOMIC VALUE ADDED PADA PT. BANK MANDIRI (PERSERO), TBK. Jurnal Bis-A: Jurnal Bisnis Administrasi, 4(1), 53-61.

Yolanda, A., Rumini, R., \& Fitra, N. (2016). PENGARUH BUDAYA ORGANISASI TERHADAP KINERJA KARYAWAN PADA PT TRAKTOR NUSANTARA CABANG MEDAN. Jurnal Bis-A: Jurnal Bisnis Administrasi, 5(1), 14-25. 